\title{
Ser, tener y leer. La identidad lectora y el capital lector: ¿son elementos clave en la configuración de las prácticas lectoras vernáculas de un adolescente de secundaria?
}

\author{
Being, having, and reading: are these key elements in \\ shaping the vernacular reading practices of middle-high \\ school students?
}

DOI: https://doi.org/10.32870/dse.v0i23.964

\section{Alma Karina Galindo Oceguera*}

\begin{abstract}
Resumen
Desde la perspectiva de los Nuevos Estudios de Literacidad y con un enfoque cualitativo, este estudio piloto se plantea dos objetivos: explorar la identidad lectora, el capital lector y la práctica lectora vernácula de un estudiante de secundaria, y valorar la pertinencia de las técnicas, los instrumentos y la estrategia para el análisis de los datos empleados para ese fin. El estudio constó de dos fases. En la primera, se realizaron observaciones de aula para identificar al informante; en la segunda, se efectuaron entrevistas semiestructuradas al informante, a su madre y a una de sus profesoras, además se solicitó al adolescente que completara un formato para el registro de sus lecturas antes de cada entrevista. Los resultados muestran que las prácticas lectoras vernáculas del informante obedecen a sus intereses y necesidades y están estrechamente vinculadas con los elementos de su identidad lectora y las diferentes manifestaciones de su capital lector. Se concluye que el formato de registro de lecturas fue inútil a su propósito, mientras que la observación, las entrevistas semiestructuradas y la estrategia para el análisis de datos demostraron ser herramientas pertinentes para la construcción de datos cualitativos en el estudio de las prácticas lectoras de adolescentes.
\end{abstract}

Palabras clave: Adolescentes - práctica lectora vernácula - identidad lectora - capital lector - Nuevos Estudios de Literacidad.

\begin{abstract}
From the New Literacy Studies perspective and with a qualitative approach, this pilot study aims to explore reading identity, reading capital, and vernacular reading practices of a middle school student, as well as to determine the relevance of techniques, instruments, and the data analysis strategy used for that purpose. In the first stage of the study, classroom observations were made to identify an informer; in the second, semi-structured interviews were carried out with the student, the student's mother and one of their teachers. The student was also asked to fill out a format to record his readings before each interview. The
\end{abstract}

\footnotetext{
* Doctora en Educación. Líneas de investigación: Literacidad y procesos educativos, literacidad, lenguaje y cultura. México. almkary@yahoo. com.mx
} 
results showed that the informer's reading practices were a response to his interests and needs and were intricately linked to the elements of his reading identity and the different manifestations of his reading capital. We concluded that the written format for reading was useless for its purpose, while observations, semi-structured interviews and data analysis strategy proved to be relevant tools for the construction of qualitative data in the study of adolescents' reading practices.

Key words: Adolescents - vernacular reading practices - reading identity - reading capital - New Literacy Studies.

\section{Introducción}

Según se ha reportado en diversos estudios, los adolescentes de secundaria realizan una diversidad de lecturas que abarca una multiplicidad de textos, como cuentos, novelas, poesías, revistas de modas o deportivas, cómics, libros de texto, páginas web, blogs, redes sociales, entre otros (Barry, 2013; Manresa, Margallo, 2016; Trigo, Santos, Sánchez, 2020; Villalpando, 2014). En tales trabajos se realizan exhaustivas revisiones sobre las características de esas lecturas, los textos leídos, los soportes utilizados o la frecuencia y duración de las lecturas, lo que ofrece un panorama general de qué y cómo leen los jóvenes de secundaria, aunque aún dejan espacio para preguntar cuáles son las razones que están detrás de estas lecturas.

Para responder al anterior cuestionamiento es necesario aproximarse a las lecturas de los adolescentes desde una visión cualitativa que permita analizar los significados otorgados a las lecturas a partir de una dimensión social y subjetiva. La corriente de los Nuevos Estudios de Literacidad (NEL) es una perspectiva útil a semejante propósito, pues concibe a la lectura y sus significados como un conjunto de prácticas situadas en diferentes contextos sociales (Barton, Hamilton, 2012). Desde este punto de vista, es posible afirmar que todo lo que los adolescentes leen en su vida diaria constituye sus prácticas de lectura, las cuales son prácticas sociales situadas que giran en torno a un texto (Gee, 2000). Siendo así, las prácticas de lectura de los adolescentes responden a determinados contextos $y$, por ende, no son homogéneas pues varían en función de los requerimientos de ese contexto en específico, de manera que coexisten, en su práctica lectora cotidiana, prácticas de lectura dominantes y vernáculas.

Las prácticas lectoras dominantes son las que se realizan principalmente en o para la escuela y constituyen el canon de la lectura. Por oposición, las prácticas lectoras vernáculas son informales, libres, espontáneas, coloquiales, y se realizan al margen de los estándares establecidos con la finalidad de atender a múltiples intereses, objetivos, metas y necesidades de la vida cotidiana (Barton, Hamilton, 2012). Estas lecturas también han sido denominadas por otros autores como lectura recreativa (Merga, 2014), lectura independiente (Knoester, 2010) o prácticas lectoras fuera de la escuela (Knoester, Plikuhn, 2016).

A partir de aquí, cabe preguntarse cómo se constituyen las prácticas lectoras vernáculas de los adolescentes y qué elementos intervienen en su configuración. Al respecto, hay autores que 
señalan que la identidad lectora y el capital lector son elementos de interés para el estudio de las prácticas lectoras vernáculas de los jóvenes (Aliagas, Castellà, Cassany, 2009; Compton-Lilly, 2007; Dallo, Soler, 2019; Jure, Peruchini, 2019; Orozco, Barahona, 2019). Por un lado, los trabajos sobre identidad lectora señalan que -siendo esta la concepción que las personas tienen sobre sí mismos con respecto a la lectura-contribuye a que los adolescentes realicen lecturas con características particulares, en ciertos momentos y con determinadas personas (Aliagas et al., 2009; Dallo, Soler, 2019; Jure, Peruchini, 2019). Por otro lado, los estudios que abordan el capital lector mencionan que este es una especie de herencia constituida por bienes materiales e inmateriales vinculados a la lectura y que la posesión o carencia de capital lector puede llegar a ser un aspecto decisivo en la configuración de las prácticas lectoras de los individuos (Compton-Lilly, 2007; Orozco, Barahona, 2019).

Tomando en cuenta las nociones anteriores, se elaboró un proyecto de investigación con la finalidad de comprender cómo se configuran las prácticas lectoras vernáculas de los adolescentes de secundaria a partir de su capital lector y su identidad lectora, en el que se planteó como objeto de estudio la relación entre estos elementos, y del cual este estudio piloto constituye una primera aproximación. Particularmente, la pregunta de investigación de este estudio piloto es ¿cómo contribuyen el capital lector y la identidad lectora en la configuración de las prácticas lectoras vernáculas del adolescente? Los objetivos son dos. El primero consistió en explorar las prácticas lectoras vernáculas de un estudiante de secundaria en relación con su capital lector y su identidad lectora. El segundo objetivo fue valorar la pertinencia de las técnicas, los instrumentos y la estrategia para el análisis de los datos utilizados en la exploración de las relaciones entre identidad lectora, capital lector y prácticas lectoras vernáculas de los adolescentes.

\section{Prácticas lectoras vernáculas, identidad lectora y capital lector}

Como ya se ha señalado, los tres conceptos de interés para este trabajo son las prácticas lectoras vernáculas, la identidad lectora y el capital lector. De acuerdo con los NEL, todas las prácticas lectoras están compuestas por un conjunto de eventos lectores, que podrían ser definidos como aquellas situaciones en las que la lectura tiene un papel protagónico. De acuerdo con Hamilton (2000), en cada evento lector se pueden distinguir cuatro elementos observables: actividad (la acción realizada en torno al texto, en este caso, una lectura vernácula), escenario o contexto (lugar físico que incluye las circunstancias sociales en las que el evento lector se desarrolla), artefactos (textos e instrumentos de lectura: libros, dispositivos electrónicos y cualquier otro material escrito), y participantes (los sujetos que integran el evento lector).

Además de estos elementos, que funcionan como marcadores que permiten identificar si se trata de un evento lector de tipo vernáculo u oficial, en el desarrollo de los eventos lectores $-y$, por ende, de las prácticas lectoras- influyen las motivaciones y los usos que las personas 
dan a esas lecturas, es decir, porqué y para qué leen. En relación con ello, Barton y Hamilton (2012) clasificaron las prácticas lectoras vernáculas de las personas en seis áreas: organización de la vida (para ordenar aspectos del día a día, como las agendas); comunicación personal (para comunicarse con amigos o familiares a través de cartas, mensajes o similares); ocio privado (realizadas por placer o entretenimiento); documentación de la vida (para recordar acontecimientos pasados de sus vidas); creación de sentido (para resolver problemas de la vida cotidiana de diversa índole); y participación social (efectuadas en la vida social con amigos, vecinos y otros).

De acuerdo con lo anterior, las finalidades, los usos y los soportes en los que son realizadas las prácticas lectoras vernáculas cambian en función de las necesidades de las personas. Particularmente los adolescentes, denominados "nativos digitales" (Prensky, 2013) por su supuesta capacidad para dominar a temprana edad diversos dispositivos digitales, frecuentemente realizan prácticas lectoras vernáculas en línea. Entre las características que destacan de estas lecturas se encuentra su brevedad, superficialidad y su carácter híbrido, pues pueden incorporar imágenes, emoticones o sonidos (Barton, Lee, 2013).

La identidad lectora es el segundo concepto de interés para este trabajo. De acuerdo con Aliagas et al. (2009), la identidad lectora puede definirse como la perspectiva que un sujeto tiene de sí mismo como lector; dicha perspectiva se construye a partir de tres elementos: uno cognitivo (ideas propias con respecto a la lectura), uno emocional (los sentimientos generados hacia la lectura) y uno social (los valores y usos asignados a la lectura). Esto significa que la identidad lectora no es un producto unidimensional, sino que es una construcción que reúne elementos sociales y personales que se relacionan estrechamente con las prácticas lectoras de los sujetos, pues involucran el agrado o desagrado por ciertos textos, las ideas con respecto a ellos y el grado de aceptación que pudieran tener en los círculos sociales en los que dichos textos son abordados.

El tercer concepto por revisar es el de capital lector. Este se desprende de la noción de capital de Bourdieu (2001), quien lo define como "trabajo acumulado", es decir, como un conjunto de bienes materiales e intangibles, estos últimos interiorizados o incorporados en los individuos. De acuerdo con Compton-Lilly (2007), el capital lector, de manera particular, hace referencia al conjunto de elementos, ya sea materiales o inmateriales, que poseen las personas y que contribuyen en su relación con la lectura. En línea con la clasificación del capital en tres tipos (económico, social y cultural) de Bourdieu (2001), Compton-Lilly (2007) señaló que es posible identificar tres formas de capital lector: capital lector económico, capital lector social y capital lector cultural.

El capital lector económico, por un lado, se refiere a las posesiones o bienes en los que se ha invertido dinero y que favorecen la lectura, como son los libros o los soportes electrónicos. Por otro lado, el capital lector social está compuesto por las personas que rodean al sujeto (familiares, amigos, profesores) y que, de diferentes formas, contribuyen en su formación lectora. 
Por último, el capital lector cultural puede existir en tres diferentes estados: capital lector cultural incorporado (prácticas de lectura interiorizadas, disposición física y mental hacia la lectura), capital lector cultural objetivado (evidencias, materiales o intangibles que demuestran la capacidad lectora) y capital lector cultural institucionalizado (trayectoria lectora e institucional, certificaciones y títulos que avalan la capacidad lectora); esta forma de capital lector también puede ser definida como la experiencia, los conocimientos y las relaciones enriquecedoras de la práctica lectora, obtenidos por un individuo a lo largo de su vida (González, 2013).

Como se puede ver, los tres conceptos abordados (práctica lectora vernácula, identidad lectora y capital lector) pueden ser desmenuzados en múltiples elementos. Para abarcarlos a todos, se realizó un abordaje metodológico que permitiera identificarlos, examinar las posibles relaciones entre ellos y explicar cómo es que se vinculan. De acuerdo con ello, en el siguiente apartado se describe con detalle la metodología utilizada.

\section{Metodología}

Este trabajo es un estudio piloto que se realizó durante el ciclo escolar 2016-2017, en los meses de marzo, abril y mayo del año 2016, como un primer paso en el desarrollo de un proyecto más amplio que contemplaba el estudio de la configuración de las prácticas lectoras vernáculas de adolescentes de secundaria a partir de su identidad lectora y su capital lector.

Se parte de una aproximación cualitativa que permitiera analizar la dimensión social y subjetiva del adolescente e indagar sobre el significado que este otorga a sus prácticas lectoras vernáculas para identificar su identidad lectora, así como el significado y el uso que atribuye a su capital lector. La unidad de análisis fueron los eventos lectores que constituyeron su práctica lectora vernácula. Particularmente, se emplearon técnicas etnográficas tales como la observación, el registro y la entrevista, empleadas en diversos trabajos de los NEL para estudiar las características de las prácticas lectoras a nivel individual, familiar o en comunidades enteras (Aliagas et al., 2009; Barton, Hamilton, 2012; Compton-Lilly, 2007).

El estudio se llevó a cabo en el turno vespertino de una escuela secundaria pública de sostenimiento estatal, urbana, ubicada en el municipio de Guadalajara, Jalisco (México) caracterizada por atender a alumnos que proceden de colonias alejadas, de clase baja y media baja, con problemas de pandillerismo, drogadicción, narcomenudeo y violencia. El primer acercamiento se realizó con el director de manera personal. Una vez otorgado el permiso para trabajar en este proyecto, se solicitó a dos profesoras y un profesor su autorización para el desarrollo del trabajo en el interior de las aulas. Se establecieron dos fases para el desarrollo del trabajo de campo, que se describen a continuación.

\section{Primera fase: Observación}

La observación es un proceso sistemático que tiene como finalidad producir información sobre un aspecto en particular, ya que proporciona una serie de descripciones que intentan captar la 
acción de los sujetos de estudio (Rodríguez, Gil, García, 1999). Las observaciones realizadas tuvieron un doble objetivo: detectar los eventos lectores de tipo vernáculo, llevados a cabo durante periodos que comprenden una sesión de clase, a partir de los elementos observables de los eventos lectores descritos por Hamilton (2000), y, con base en ello, identificar posibles informantes.

Se llevaron a cabo observaciones de aula en tres grupos de la secundaria en la que se realizó el trabajo, uno de cada grado: primero, segundo y tercero, durante tres sesiones no consecutivas de las clases de Historia de Jalisco, Historia, y Formación Cívica y Ética, respectivamente. Estas observaciones se efectuaron mediante una selección de muestras por intervalos breves hasta lograr la saturación teórica, lo que implicó anotaciones en el diario de campo cada cinco minutos durante los 45 minutos de sesiones de clase hasta que los registros dejaran de proporcionar información nueva (Rodríguez et al., 1999).

Se encontró que en primer grado no hubo presencia de eventos lectores vernáculos, mientras que en segundo y particularmente en tercer grado se registró un mayor número de eventos lectores vernáculos y se identificaron ahí a dos de los posibles informantes. Para averiguar si la ocurrencia de estas lecturas en este grupo variaría en la clase de otro profesor y materia, se realizó una cuarta observación. Como resultado, se encontró una menor ocurrencia de prácticas lectoras vernáculas, pero aun fue posible detectar varios eventos lectores vernáculos durante esta clase.

Un primer acercamiento a uno de los posibles informantes detectados se realizó el mismo día en que se completó la cuarta observación de aula. Sin embargo, el alumno mostró poca disposición para formar parte del estudio, así que, días después se buscó a otro joven, Daniel (su nombre real ha sido protegido), identificado como probable informante. En una breve entrevista que no fue audiograbada, se le explicó al estudiante sobre los motivos del trabajo y se le invitó a participar en la investigación, a lo que el joven accedió, por lo que se le solicitó el número de teléfono de su madre, con la finalidad de llamarla y pedir su autorización.

\section{Segunda fase: entrevistas y autorregistro de lectura}

La entrevista es una técnica confiable que permite producir datos de manera sistemática, ya que se trata de un encuentro interactivo en el que el conocimiento se construye alrededor de preguntas y respuestas, otorga la posibilidad de comprender, más que explicar, los diferentes significados que las personas atribuyen a las diversas situaciones de su vida (Fontana, Frey, 2000). En este trabajo se realizaron entrevistas semiestructuradas, pues estas permiten comprender la perspectiva del entrevistado sobre sus propias experiencias y vivencias personales en relación con el tema particular de la lectura, a partir del seguimiento, no de preguntas previamente elaboradas sino de una lista general de aspectos por cubrir (Taylor, Bogdan,1987). Esta lista se configuró como un guion de las entrevistas, que se muestra en la tabla 1. En ella se detallan los temas que se abordaron durante las entrevistas realizadas a Daniel, a su madre y a su profesora. 
Los temas fueron elegidos y conformados al considerar cada uno de los elementos que interesaban al objeto de estudio: las características de las prácticas lectoras vernáculas (eventos lectores, motivaciones y usos de la lectura), los componentes de la identidad lectora (cognitivo, emocional y social), y las formas de capital lector (económico, social y cultural), mismos que fueron extraídos de los referentes teóricos (Aliagas et al., 2009; Barton, Hamilton, 2012; ComptonLilly, 2007; Hamilton, 2000; González, 2013).

Tabla 1. Guion de las entrevistas

\begin{tabular}{|c|c|c|}
\hline Entrevistas realizadas a Daniel & $\begin{array}{c}\text { Entrevistas realizadas a la madre } \\
\text { de Daniel }\end{array}$ & $\begin{array}{c}\text { Entrevistas realizadas a la profe- } \\
\text { sora }\end{array}$ \\
\hline \multicolumn{3}{|c|}{ Identidad lectora } \\
\hline Qué considera como lectura. & $\begin{array}{l}\text { Qué considera como lectura, us- } \\
\text { ted y su hijo. }\end{array}$ & $\begin{array}{l}\text { Qué considera como lectura, usted } \\
\text { y su alumno. }\end{array}$ \\
\hline $\begin{array}{l}\text { Valor asignado a la lectura. Gus- } \\
\text { to por la lectura. ¿Le gusta leer? }\end{array}$ & $\begin{array}{l}\text { Valor que percibe es asignado a la } \\
\text { lectura por su hijo. ¿Le gusta leer? }\end{array}$ & $\begin{array}{l}\text { Valor que percibe es asignado a la } \\
\text { lectura por su alumno. ¿Le gusta } \\
\text { leer? }\end{array}$ \\
\hline $\begin{array}{l}\text { Se considera buen/mal lector. } \\
\text { Qué le hace falta para ser buen } \\
\text { lector. Cómo se ve a sí mismo: } \\
\text { grupos con los que se identifica. }\end{array}$ & $\begin{array}{l}\text { Considera buen/mal lector a su } \\
\text { hijo. Qué le hace falta para ser } \\
\text { buen lector. Cómo ve a su hijo: } \\
\text { grupos con los que este se iden- } \\
\text { tifica. }\end{array}$ & $\begin{array}{l}\text { Considera buen/mal lector a su } \\
\text { alumno. Qué le hace falta para ser } \\
\text { buen lector. Cómo ve a su alumno: } \\
\text { grupos con los que este se identi- } \\
\text { fica. }\end{array}$ \\
\hline \multicolumn{3}{|c|}{ Prácticas lectoras vernáculas } \\
\hline $\begin{array}{l}\text { Razones, objetivos, intereses y } \\
\text { motivaciones por los que lee. }\end{array}$ & $\begin{array}{l}\text { Razones, objetivos, motivaciones } \\
\text { e intereses por los que usted pien- } \\
\text { sa que su hijo lee. }\end{array}$ & $\begin{array}{l}\text { Razones, objetivos, motivaciones } \\
\text { e intereses por los que su alumno } \\
\text { lee. }\end{array}$ \\
\hline $\begin{array}{l}\text { Lecturas realizadas. } \\
\text { Lugares, situaciones, momentos } \\
\text { o actividades en los que lee y } \\
\text { tiempo destinado a ello. }\end{array}$ & $\begin{array}{l}\text { Lecturas realizadas por su hijo. } \\
\text { Lugares, situaciones, momentos } \\
\text { o actividades en los que observa } \\
\text { leer a su hijo y tiempo destinado } \\
\text { a ello. }\end{array}$ & $\begin{array}{l}\text { Lecturas realizadas por su alumno. } \\
\text { Lugares, situaciones y momentos } \\
\text { en los que el alumno lee y tiempo } \\
\text { destinado a ello. }\end{array}$ \\
\hline \multicolumn{3}{|c|}{ Capital lector (económico, social y cultural) } \\
\hline $\begin{array}{l}\text { Artefactos de lectura que posee } \\
\text { (teléfonos inteligentes, libros, } \\
\text { computadoras, tabletas, revis- } \\
\text { tas). }\end{array}$ & $\begin{array}{l}\text { Artefactos de lectura que su hijo } \\
\text { posee (teléfonos inteligentes, } \\
\text { libros, computadoras, tabletas, } \\
\text { revistas). }\end{array}$ & $\begin{array}{l}\text { Artefactos de lectura que posee } \\
\text { su alumno (teléfonos inteligentes, } \\
\text { libros, computadoras, tabletas, } \\
\text { revistas). }\end{array}$ \\
\hline $\begin{array}{l}\text { Influencias familiares/sociales } \\
\text { para realizar lecturas. }\end{array}$ & $\begin{array}{l}\text { Influencias familiares/sociales } \\
\text { para realizar lecturas. }\end{array}$ & $\begin{array}{l}\text { Influencias familiares/sociales que } \\
\text { percibe en su alumno para realizar } \\
\text { lecturas. }\end{array}$ \\
\hline $\begin{array}{l}\text { Comportamiento en situaciones } \\
\text { de lectura. Desempeño en lec- } \\
\text { tura. }\end{array}$ & $\begin{array}{l}\text { Comportamiento de su hijo en } \\
\text { situaciones de lectura. Desempe- } \\
\text { ño en lectura. }\end{array}$ & $\begin{array}{l}\text { Comportamiento de su alumno en } \\
\text { situaciones de lectura. Desempe- } \\
\text { ño en lectura. }\end{array}$ \\
\hline
\end{tabular}

Fuente: elaboración propia. 
Se realizó una entrevista a la madre de Daniel, una a la profesora de la clase que permitió realizar las observaciones de aula y se efectuaron cuatro entrevistas a Daniel. La entrevista con la madre se realizó en un restaurante cercano a su trabajo tuvo una duración de alrededor de dos horas y no fue audiograbada. En ella se le solicitó que firmara un documento de consentimiento informado, basado en el Formato de Consentimiento Informado para Estudios Cualitativos de la Organización Mundial de la Salud (WHO, 2017). Mediante este documento se le informó sobre las particularidades del estudio y se garantizó la confidencialidad de la información recabada mediante el empleo de seudónimos, la omisión de los nombres de lugares y domicilios, así como el uso ético de esta información (González, 2002).

La entrevista a la profesora de Daniel se realizó durante el tiempo libre de la maestra, tuvo una duración aproximada de 20 minutos y fue audiograbada. Las cuatro entrevistas realizadas a Daniel tuvieron lugar dentro de las instalaciones de la secundaria (mesas de los patios, sala de maestros), en los horarios asignados para la clase de Formación Cívica y Ética. Tres de estas entrevistas tuvieron una duración aproximada de media hora, y una de diez minutos. Antes de la primera entrevista se le solicitó que, al igual que su madre, leyera y firmara un documento de consentimiento informado.

Una sesión antes de cada entrevista se solicitó a Daniel que completara un formato denominado "Autorregistro de lectura", elaborado a partir del instrumento utilizado por Martínez (2014) para el autorregistro de lecturas vernáculas y oficiales. En este formato se le pedía al joven que escribiera las lecturas realizadas en casa y en la escuela durante el día anterior a cada una de las entrevistas. Estas lecturas podrían ser, a su juicio, escolares o no escolares; también debía especificar si dichas lecturas fueron realizadas en papel (libros, cuadernos) o en formato electrónico (computadora, teléfono celular) y cuánto tiempo duraron. Daniel, sin embargo, nunca rellenó ni entregó a la entrevistadora ni uno solo de los autorregistros de lectura; al ser cuestionado sobre ello durante las entrevistas, el joven mostró su desinterés al alegar que esa actividad solo era "como una tarea más".

\section{Análisis e interpretación de los datos}

El análisis de los datos se realizó en tres etapas, siguiendo el enfoque de Taylor y Bogdan (1987), orientado hacia la comprensión de las personas y los contextos. De acuerdo con González (2013: 44), este enfoque permite crear "tipologías, categorías, conceptos y proposiciones teóricas".

Primera etapa: Las dos fuentes de datos obtenidas (notas de campo sobre las observaciones realizadas en el aula y grabaciones de las entrevistas) fueron transcritas en archivos de texto. Se realizó una lectura repetida de estos textos con la finalidad de categorizar los datos y realizar interpretaciones preliminares.

Segunda etapa: Se establecieron subcategorías de análisis a partir de cada una de las categorías previamente identificadas, de acuerdo con los conceptos provenientes de los referentes teóri- 
cos (Aliagas et al., 2009; Barton, Hamilton, 2012; Compton-Lilly, 2007). Mediante las categorías y subcategorías establecidas se organizaron y clasificaron los datos brutos (diario de campo, entrevistas y autorregistros) para vincular la realidad observada con la teoría. Las categorías con sus subcategorías correspondientes, así como el referente teórico de donde procede, pueden observarse en la tabla 2.

Tabla 2. Categorías y subcategorías identificadas durante la segunda etapa del análisis

\begin{tabular}{|c|c|c|c|}
\hline Categorías & \multicolumn{2}{|r|}{ Subcategorías } & Referentes \\
\hline \multirow{6}{*}{$\begin{array}{l}\text { Prácticas } \\
\text { lectoras } \\
\text { vernáculas }\end{array}$} & $\begin{array}{l}\text { Organización } \\
\text { de la vida }\end{array}$ & $\begin{array}{l}\text { Prácticas de lectura necesarias para poner en orden as- } \\
\text { pectos de la vida diaria. }\end{array}$ & \multirow{6}{*}{$\begin{array}{l}\text { Barton y } \\
\text { Hamilton } \\
\text { (2012) }\end{array}$} \\
\hline & $\begin{array}{l}\text { Comunicación } \\
\text { personal }\end{array}$ & Intercambio de textos entre familiares y amigos. & \\
\hline & Ocio privado & Entretenimiento o placer, generalmente privado. & \\
\hline & $\begin{array}{l}\text { Documenta- } \\
\text { ción de la vida }\end{array}$ & $\begin{array}{l}\text { Lectura de documentos que atestiguan acontecimientos } \\
\text { pasados de la vida de las personas o de sucesos importan- } \\
\text { tes para ellas. }\end{array}$ & \\
\hline & $\begin{array}{l}\text { Participación } \\
\text { social }\end{array}$ & $\begin{array}{l}\text { Lecturas que tienen lugar dentro de un grupo social de- } \\
\text { terminado, con fines específicos. }\end{array}$ & \\
\hline & $\begin{array}{l}\text { Creación de } \\
\text { sentido }\end{array}$ & $\begin{array}{l}\text { Encaminadas a la resolución de problemas cotidianos. } \\
\text { Búsqueda de información por curiosidad. }\end{array}$ & \\
\hline \multirow{3}{*}{$\begin{array}{l}\text { Identidad } \\
\text { lectora }\end{array}$} & $\begin{array}{l}\text { Componente } \\
\text { cognitivo }\end{array}$ & Creencias sobre la lectura. & \multirow{3}{*}{$\begin{array}{l}\text { Aliagas et al. } \\
\quad(2009)\end{array}$} \\
\hline & $\begin{array}{l}\text { Componente } \\
\text { emocional }\end{array}$ & $\begin{array}{l}\text { Emociones positivas/negativas hacia la lectura, senti- } \\
\text { mientos provocados por la lectura. }\end{array}$ & \\
\hline & $\begin{array}{l}\text { Componente } \\
\text { social }\end{array}$ & $\begin{array}{l}\text { Pertenencia a un grupo determinado, roles desempeña- } \\
\text { dos, valores asignados a la lectura. }\end{array}$ & \\
\hline \multirow{3}{*}{$\begin{array}{l}\text { Capital } \\
\text { lector }\end{array}$} & $\begin{array}{l}\text { Capital lector } \\
\text { social }\end{array}$ & $\begin{array}{l}\text { Redes sociales que pueden servir para llevar a cabo prác- } \\
\text { ticas lectoras. }\end{array}$ & \multirow{3}{*}{$\begin{array}{l}\text { Compton- } \\
\text { Lilly (2007) }\end{array}$} \\
\hline & $\begin{array}{l}\text { Capital lector } \\
\text { económico }\end{array}$ & $\begin{array}{l}\text { Posesiones que involucran una inversión monetaria y que } \\
\text { pueden contribuir a las prácticas lectoras. }\end{array}$ & \\
\hline & $\begin{array}{l}\text { Capital lector } \\
\text { cultural }\end{array}$ & $\begin{array}{l}\text { Disposición física y mental hacia la lectura. } \\
\text { Evidencias que demuestran la competencia lectora. Cali- } \\
\text { ficaciones, títulos o certificaciones que la avalan. }\end{array}$ & \\
\hline
\end{tabular}

Fuente: Elaboración propia.

Tercera etapa: Se articularon las categorías de análisis y se elaboró una interpretación. Para lograr esto se realizaron esquemas de clasificación que permitieron identificar los patrones o relaciones entre temas y categorías; la interpretación final consistió en un procedimiento de re- 
lativización de los datos, que implicó la consideración del contexto y la forma en que los datos fueron construidos (Coffey, Atkinson, 2003; Taylor, Bogdan, 1987).

\section{Resultados}

Se encontró que los tres conceptos involucrados en la pregunta de investigación (prácticas lectoras vernáculas, identidad lectora y capital lector) se encuentran íntimamente relacionados, pues sus elementos se entrelazan de manera orgánica, es decir, se influyen unos a otros como si de un sistema vivo se tratara; pero, para mayor claridad en su exposición, los resultados se dividieron en tres áreas que corresponden a cada uno de ellos.

\section{Las prácticas lectoras vernáculas de Daniel}

Daniel es un joven de 15 años que estudia el tercer grado de secundaria. Cuando se inició el estudio, Daniel tenía apenas un par de meses de haber ingresado al turno vespertino, ya que antes estudiaba en el turno matutino de la misma escuela, pero fue enviado al de la tarde "como castigo". Los padres son divorciados y ambos tienen estudios universitarios. Daniel es el segundo de tres hijos y el único varón. Actualmente vive con su madre y su hermana de 10 años; su hermana mayor vive cerca y tiene dos niños pequeños, los frecuenta. Tienen una posición económica que podría clasificarse como media.

Las prácticas lectoras vernáculas de Daniel obedecen a diferentes necesidades y situaciones. Siguiendo la clasificación de las prácticas lectoras vernáculas de Barton y Hamilton (2012), se encontró que Daniel realiza lecturas para la "organización de la vida", la "comunicación personal", el "ocio privado", la "participación social"y "creación de sentido".

\section{Organización de la vida}

Las prácticas lectoras para organizar la vida consisten en lecturas que tienen como objetivo ordenar asuntos cotidianos no oficiales. Las lecturas realizadas por Daniel con esta finalidad generalmente consisten en consultar su teléfono inteligente para seleccionar y organizar las canciones de sus géneros favoritos (rap, hip hop y trap) que desea escuchar con audífonos; esta acción implica realizar breves lecturas de los títulos de las canciones, los discos y los textos incluidos en la interfaz del reproductor de música. Este tipo de lecturas se corresponden con las señaladas por Barton y Lee (2013) para organizar la vida en medios digitales. De acuerdo con estos autores, las tecnologías han cambiado la forma en la que las personas leen, pues antes de los teléfonos inteligentes, realizar lecturas para escuchar música -aunque fueran breves- era diferente, se leían las portadas de los discos para elegirlos u organizarlos en el espacio destinado a ellos en el hogar si se poseía un medio de reproducción, o no se leía en absoluto si se escuchaba la radio. Las lecturas para organizar la vida se realizan para asuntos cotidianos de interés para las personas, y en el caso de Daniel, organizar la música en el teléfono es un asunto relevante, dada la importancia -como se verá más adelante- que tiene la música en su vida. 


\section{Comunicación personal}

Las lecturas para la comunicación personal de Daniel implican el intercambio de textos con amigos, compañeros y familiares, tanto en medios analógicos como digitales, con diversas finalidades, como el cotilleo, el flirteo o la transmisión de información. Estas formas de lectura, que también implican escritura, a veces involucran más de dos participantes, y en ocasiones, a casi todo el grupo al que Daniel pertenece. Los chismes que circulan en el aula son cuestiones de interés para los estudiantes, alejadas del tema que se ve en clase:

E: Por ahí me he enterado que se rolan papelitos.

Daniel: Sí.

$E$ : Tú me puedes platicar en qué consiste ese juego o no sé si es juego...

Daniel: No... ps solamente p-como-como lo comento digo en ocasiones que el maestro dice ah silencio y no sé qué tanto $y$, con tal de no estar jodiendo o... no tener al maestro encima, s-se hace el papel y se cuenta el mismo chisme o... I-no sé lo mismo que estabas platicando al momento.

E: $\mathrm{mmm}$ ¿podrías platicarme un ejemplo de un chisme?

Daniel: Hey, na ps... como por ejemplo que ah fulanito de tal anda detrás de... fulanita de tal porque lo quiere madrear porque... le hizo ¿cómo se llama? Le andanda-andaba hablándole bonito otra a su novia y no sé que tanto, cosas así por el estilo.

E: ¿Y qué van poniendo ahí?

Daniel: Pues si ah si que ah no jodas ¿es en serio? Que... tus reacciones y eso supongo que lo que dirías en el momento (Entrevista a Daniel No. 3).

Es interesante, además, que los compañeros de Daniel prefieran utilizar papeles en vez de mensajes por el celular por cuestiones económicas, ya que no todos tienen señal wifi o datos de prepago, lo que podría ser un ejemplo de los efectos que el capital lector, en este caso económico, puede tener sobre las características de las prácticas lectoras vernáculas.

De acuerdo con la maestra entrevistada, estas lecturas son "algo muy personal" de los alumnos, pero también se trata de actividades que no deberían realizarse durante la clase, por lo que, cuando detecta este tipo de lecturas, pide a sus alumnos que le den su teléfono celular o que tiren a la basura los papeles que se pasan. Esto muestra que existen tensiones entre las prácticas escolares y las prácticas de lectura vernácula cuando confluyen en el aula, pues las segundas son generalmente prácticas clandestinas, prohibidas o censuradas en ese contexto, lo que ha sido reportado en otros trabajos (Hernández, 2009).

Aunque Daniel refiere no utilizar con frecuencia las aplicaciones de mensajería instantánea para comunicarse con sus amigos, su madre expresó que ella y su hijo intercambian mensajes por WhatsApp con la finalidad de comunicarse asuntos "sobre sentimientos". Para ella, esta es una forma mediante la cual Daniel logra explicarse y mostrar lo que piensa y siente sobre alguna situación en particular. 


\section{Ocio privado}

Las prácticas lectoras por ocio privado tienen que ver con la recreación, el entretenimiento y el placer. Los géneros de lectura que gustan a Daniel son la ciencia ficción y los cómics, aunque también ha leído algo de poesía. Estas lecturas son realizadas en libros y cómics en físico y digitales. Algunos de los libros análogos que ha leído son El Código da Vinci, Fahrenheit 451, Nuevas peregrinaciones (poesía), Punto ciego. De los libros digitales, mencionó Planeta Misterio, aunque no lo ha terminado. Además, aunque posee algunos cómics en físico, la mayoría de los que ha leído son cómics gratuitos en línea a través de Facebook:

E: El otro día me dijiste que en internet sueles ver cómics historietas en Face, [...] me gustaría saber de qué van. Que me platicaras...

Daniel: Pues... son rollitos así como el... Iron Man y todo eso, superhéroes y cosas así por el estilo, un poco aniñado pero pues sinceramente me importa un pepino, porque a mí me gusta y pues... lo disfruto.

E: ¿Y cuánto tiempo estás viendo historietas, digamos, en una semana?

Daniel: No lo sé, fíjate que cuando le agarro el rollito es como que... también te enganchas así como que... sabe no-no es como un libro común digo, tiene el arte visual y pues te puedes ir guiando y ya no solamente por tu cabeza, sino pues... tienes ahí eso para que te guíe, digo... y... me agrada eso de los cómics sabes así- eh... algo, un punto extra a favor de, de esos. Pero... yo diría que, a la semana... me tiré, me tiro como... ocho horas en conjunto de toda la semana (Entrevista a Daniel No. 4).

La lectura de textos en línea por ocio privado no se limita a los cómics. Además, hay lecturas que Daniel realiza en internet que tienen que ver con memes y publicaciones en la red social Facebook que llaman su atención y lee por curiosidad. Estas lecturas son muy breves y generalmente se componen de chistes, bromas y textos que combinan imágenes.

Otras lecturas relacionadas con el ocio privado son la lectura de subtítulos en películas no dobladas al español. Un dato interesante con respecto a esto es que Daniel no acostumbra a ver películas subtituladas, solo lo hace cuando esta le interesa mucho, y si el interés no es demasiado, espera a que la película esté disponible en su versión doblada al español. Lo anterior es llamativo ya que esto podría vincularse con los resultados obtenidos en trabajos que muestran que la motivación y el interés incentivan la lectura en los adolescentes, aunque estas lecturas representen una mayor dificultad (Fulmer, Tulis, 2013).

Como se puede ver, las prácticas lectoras por ocio privado de Daniel son realizadas tanto en medios análogos como en medios digitales y van desde la brevedad y la inmediatez, hasta lecturas que implican una inversión mayor de tiempo y esfuerzo. Como señalan algunos autores (Barton, Lee, 2013; Valdez, 2017), la lectura se realiza en la vida en línea y fuera de línea, en un continuo que obedece a las necesidades específicas del momento, pero también al acceso a conexiones de internet y la disponibilidad de los artefactos. 


\section{Participación social}

Las lecturas para la participación social de Daniel, generalmente, implican la interacción con sus pares, es decir, amigos y compañeros de clase, tanto en línea como fuera de línea. En la escuela, Daniel y su amigo Víctor escriben e intercambian canciones de rap con la finalidad de leerlas y comentarlas de manera crítica. La valoración de las letras de las canciones que escribe su amigo enriquece a Daniel, pues al estar consciente de que se trata de textos personales, íntimos, genera sentimientos positivos al respecto, le "parece bien que [su amigo Víctor] le tenga confianza".

Al mismo tiempo que lee los textos de su amigo, Daniel escribe canciones de hip hop y rap como una forma de ocio que le permite expresarse; además, se ha involucrado en la escena urbana de este género de música y ha interpretado sus letras en algunos eventos organizados por este mismo círculo. Daniel comenzó a relacionarse con el ambiente del rap, trap y hip hop a través de Facebook:

E: ¿Qué haces con tus canciones? ¿las guardas?

Daniel: Las guardo y en ocasiones... pues un... en ocasiones voy y las grabo, un amigo tiene un estudio casero y pues... hace... hace el favor, el paro, como quieras llamarlo, de... pues grabarlas y poderlas subir a Youtube o cosas por el estilo.

E: ¿Dónde conociste a tu amigo?

Daniel: Por el internet. Es que... pasa que, que en algunos grupos de Facebook o... páginas y así... no lo sé, pones algún post de que alguien que me graba un tema o cosas por el estilo... y pues salen, y pues... fue él que me comentó a mí, así que... fui a su domicilio, grabamos y pues surgió un cotorreo y... pues me agradó el tipo y como que también hubo ahí así como, como que ese pique de que, pues no solamente fue por negocio... y pues ya posterior segui yendo y yendo y pues, creo que se desarrolló, puedo entablar eh, no una amistad pero sí algo, una relación... ma-más seria, no solamente por negocio (Entrevista a Daniel No. 3).

Como otros autores señalan, la lectura permite la socialización, pero también la socialización permite la lectura (Barton, Lee, 2013; Manresa, Margallo, 2016). Ya sea a través de medios análogos o en línea, las prácticas lectoras para la participación social posibilitan a los jóvenes el acceso a personas y espacios, es decir, a adquirir capital lector social. Este capital lector social, al mismo tiempo, enriquece las prácticas lectoras de los jóvenes, pues en ese intercambio conocen a otros autores, otros escritos, otros textos y les dan la posibilidad, como señala Hernández (2009), de ampliar su mirada hacia otras perspectivas del mundo que de otra manera no habrían conocido.

\section{Creación de sentido}

Las prácticas lectoras para la creación de sentido de Daniel consisten en lecturas sobre varios temas que mueven su curiosidad. Ha leído tres libros de superación personal de Paulo Coelho en formato digital, diversas páginas en internet con información relevante para él (sobre las 
drogas o noticias) y folletos de los Testigos de Jehová. Estos últimos le parecieron "muy fantasiosos", mientras que los libros de Paulo Cohelo no le agradaron. En relación con los textos sobre las drogas que ha leído en internet, Daniel intenta encontrar información que dé sentido a sus preguntas sobre estas sustancias, que se ha guardado quizá porque, como él lo señala, se trata de un tema "tabú":

E: ¿Qué otras cosas has descubierto por internet?

Daniel: ... pues distintos temas en general, sabes, como, como que las ondas tripi y psicodélicas.

E: ¿Qué es tripi y psicodelia? ¿A qué te refieres?

Daniel: Con... no lo sé, con algún tipo de información sobre... drogas psicodélicas, como lo que vendrían siendo los hongos, el LSD, el DMT, cosas por el estilo, que no sé, que te saquen eh ese tabú, que no sé qué, que ah son malas porque te... causan tal tal tal tal tal, te... que no solamente queda en eso, no niegan que tienen algunos... bueno, no algunos, sino que pues son dañinas porque es una droga... pero que también puede tener algunos efectos positivos o... o información sobre la misma y porqué surgió la droga o... si, o quién la inventó o... o qué pasó ese mismo día que la inventó o porqué surgió o cosas por el estilo no solamente, quedarte ahí con esa incertidumbre de que ah jes una droga, es mala!Y te hace mucho daño, es ilegal, no, tan tan, punto, no, es que no. Saber por qué es ilegal, por qué... ¿cómo se llama? Porqué... tiene ese mismo efecto, porqué surgió, porqué, por-porqué, su razón de ser (Entrevista a Daniel No. 3).

Con estas lecturas, Daniel intenta responder a sus cuestionamientos, informarse y formarse una opinión propia con respecto al uso de las drogas, entender cuáles son sus efectos y por qué pueden hacer daño. De acuerdo con Barton y Lee (2013), es una práctica habitual buscar información en internet ante dudas de la vida cotidiana. Estas búsquedas ayudan a las personas a tomar decisiones.

\section{La identidad lectora de Daniel}

Como ya se mencionó páginas arriba, la identidad lectora es la perspectiva, cambiante, nunca estática, que cada persona tiene de sí misma en relación con la lectura, en la que confluyen e interactúan el componente cognitivo, el emocional y el social (Aliagas et al., 2009). En Daniel, estos tres componentes configuran una perspectiva propia, una ideología personal con respecto a la lectura, que se detalla en los tres siguientes apartados.

\section{Componente cognitivo}

El componente cognitivo de la identidad lectora hace referencia a las ideas y creencias que una persona tiene sobre la lectura. Para Daniel, la lectura es un medio que le permite entretenerse, comunicarse y conocer otros lugares sin salir de casa: 
Ser, tener y leer. La identidad lectora y el capital lector: ¿son elementos clave en la configuración de las prácticas lectoras vernáculas de un adolescente de secundaria?

E: ¿Qué es para ti la lectura?

Daniel: Pues... no lo sé principalmente... que ehm... no lo sé ps algo para distraernos sabes algo como para hacer pasar el rato... pues... pienso que la lectura puede ser un gran medio de comunicación sabes algo así como que estoy escribiendo lo que está pasando en tal lado y quiero que gente se entere de esta situación o cosas así por el estilo, como... o también poco como un transporte hacia otro mundo ¿sabes? Como... no lo sé, como viajar dentro de tu misma casa, el mismo lugar en el que estás, conocer otras historias (Entrevista a Daniel No. 2).

Pareciera que esta descripción de la lectura que ofrece Daniel parte de una concepción que asocia la lectura con el placer y el entretenimiento, pero también con la idea de la lectura como una herramienta comunicativa, mediante la que el que escribe y el que lee dialogan, se comunican ideas. También comprende que no todas las lecturas son iguales y que hay diferentes tipos de textos con temas muy distintos y calidades diferentes. Así, señala que los libros de poesía pueden mostrar una realidad cruda y no necesariamente "feliz", que algunos textos son fuentes de historias, como los cómics, y que hay libros, como los de superación personal, con los que no comparte las mismas ideas.

Daniel se considera a sí mismo un "buen lector", pero "flojo" como estudiante. Como en el trabajo realizado por Aliagas et al. (2009), en el que se dio seguimiento a un adolescente para documentar sus prácticas de lectura, Daniel tiende a mostrar desinterés por las lecturas académicas, pero se interesa por textos al margen de los oficiales y sus prácticas lectoras vernáculas son diversas. Para leer un texto, este debe causarle curiosidad, interés:

E: ¿Y tú cómo te consideras a ti como estudiante?

Daniel: Flojo. Bastante de hecho. No lo sé.

E: ¿Y como lector?

Daniel: $\mathrm{mmm}$ pues... supongo que bueno... pues... buen lector supongo.

E: ¿Por qué?

Daniel: No lo sé, digo... me atrae la, la lectura, alguna buena historia o... o algunos algún libro de poesía que me pueda interesar o solamente el hecho de querer saber más sobre, sobre el tema que esté tratando el libro, algún libro de historia que no se, puede que sea el de... el mismo de la escuela o... alguno que te dé un detalle extra, que se meta más a fondo en el tema, digo pues... supongo que por eso.

E: ¿Te gusta leer tus libros de texto?

Daniel: mmm pues no- no tanto, de hecho... creo que el que más me gusta leer es el de historia, pero pues no es muy... muy seguido que lo lea, digo así de lleno fuera de la escuela (Entrevista a Daniel No. 3).

Como se puede observar, Daniel es consciente de que es buen lector de textos vernáculos y de que sus lecturas se encuentran al margen de las lecturas oficiales. Aunque no cumple a cabalidad con los requisitos académicos y es considerado como flojo por ello, Daniel ha logrado incorporar elementos de la cultura lectora a su alrededor y utilizarlos para sus propios fines, 
construyendo así una imagen de sí mismo como lector no escolar, para quien la lectura no implica efectuar tareas o memorizar, sino viajar, comunicarse y entretenerse.

\section{Componente emocional}

El componente emocional de la identidad lectora involucra las emociones y sentimientos generados por y a través de la lectura. Las diversas formas de lectura provocan distintas emociones y sentimientos en Daniel. Con la poesía experimentó desconcierto pues no comprendía lo que leía, hasta que, con persistencia, fue entendiendo, "agarrando el rollito". Con textos como Romeo y Julieta se sintió estresado y abandonó su lectura. Con la narración y los cómics se mete en la trama, pues le gustan las historias, las disfruta:

E: ¿Y con los libros... con las novelas?

Daniel: Pues... sabes yo leo y me lo imagino en la cabeza y me estoy imaginando como... una cinemática, o como si fuera eso como si fuera también una película y.... y pues sí, en ocasiones sí... sí te llegan varias cosas que pueden pasar ahí (Entrevista a Daniel No. 2).

Por un lado, las emociones positivas de Daniel hacia la lectura generalmente están vinculadas con sus lecturas vernáculas. Hay una preferencia particular por las narraciones, las lecturas que contienen historias, a partir de las cuales es capaz de "elaborar su propia película", como señala Petit (2011), de crear imágenes que le llevan a la ensoñación y la recreación, al ocio privado e íntimo diálogo con el autor.

Por otro lado, las emociones de desagrado van casi siempre de la mano de lecturas y tareas escolares para las que le es difícil encontrar una motivación para realizarlas, aunque también hay lecturas vernáculas que le han causado desagrado (como Romeo y Julieta y los libros de superación) y que ha abandonado por ese motivo. Al igual que en otros estudios (Aliagas et al., 2009; Cassany, Hernández, 2012; Jure, Peruchini, 2019) en los que se muestra que los jóvenes invierten mayor tiempo y esfuerzo en lecturas vernáculas que son de su agrado e interés y desdeñan las lecturas académicas impuestas por los docentes, Daniel experimenta dificultades para invertir su tiempo en lecturas que le causan "apatía, flojera", no le agradan o que son obligatorias como las escolares.

\section{Componente social}

El componente social de la identidad lectora implica la pertenencia a un grupo o grupos, los roles desempeñados en ellos, así como los valores asignados a la lectura. Las percepciones de los demás sobre la relación de Daniel con la lectura también forman parte de este componente social. Es posible que la autodefinición de Daniel como "buen lector" pero "flojo", tenga soporte en el rol que ha asumido en los contextos en los que se desenvuelve (escuela, casa, con los amigos) y también en las creencias de los demás (padres, maestros) con respecto a su relación con 
Ser, tener y leer. La identidad lectora y el capital lector: ¿son elementos clave en la configuración de las prácticas lectoras vernáculas de un adolescente de secundaria?

la lectura. Es interesante entonces que para su madre, Daniel "es inteligente pero flojo para la escuela". Por su parte, la profesora asegura que a Daniel no le gusta leer:

E: ... ¿Cómo es (Daniel en tu salón)? Platícame un poquito de él.

Maestra: Bueno, Daniel es muy distraído, ¿si? A lo que yo veo no le, no le gusta, no le gusta leer. No le gusta leer... Pero como que hace sus actividades por obligación para no reprobar la materia, pero que le guste la materia es muy aparte con la materia, no es su fuerte. Aparte que probablemente va a la escuela por obligación. Yo siento así a Daniel, que va por obligación, no porque le guste (Entrevista a la profesora de Daniel).

Daniel no responde a la imagen de lector que se tiene en espacios como la escuela, pues no cumple con todas las actividades que se le solicitan ni se interesa por los contenidos académicos. Se ha formado ante los miembros de su círculo familiar y escolar una identidad de estudiante "flojo", pues como otros autores han señalado, en estos espacios se valoran más los textos y las lecturas oficiales. Al respecto, los NEL señalan que si bien la lectura requiere el desarrollo de habilidades cognitivas, en ella intervienen también elementos sociales y culturales que no suelen ser contemplados por los métodos de enseñanza más tradicionales, en los que se preconiza una visión cognitivista de la lectura y cuya apreciación permea otros espacios sociales como la familia (Barton, Hamilton, 2012). En esta misma línea, Cassany y Hernández (2012) sostienen que los jóvenes tienden a desdeñar las tareas escolares porque para realizarlas tienen que apegarse a reglas que están desvinculadas de su quehacer diario, de sus prácticas sociales, y personalmente no les significan nada. Según Petit (2011), hay jóvenes que incluso señalan que "la escuela les había quitado el gusto por leer, porque lo había convertido en una obligación" (p.160). La lectura de textos que no significan nada a los jóvenes produce este tipo de aversiones; en el caso de Daniel, esto ha contribuido en la configuración de una identidad lectora dicotómica: un lector escolar flojo, pero buen lector de textos vernáculos.

\section{El capital lector de Daniel}

Las entrevistas realizadas permitieron bosquejar el capital lector de Daniel, que en su totalidad se compone de los elementos que integran su capital lector económico, social y cultural. En los siguientes tres apartados se detallan las características de cada uno de ellos.

\section{Capital lector económico}

El capital lector económico se refiere a la posesión de artefactos o dispositivos de lectura que han sido o pueden ser intercambiados por dinero y que contribuyen en la realización de las prácticas lectoras (Compton-Lilly, 2007). Daniel tiene un teléfono inteligente propio, acceso a internet en casa y una laptop que comparte con su madre y hermana pequeña; estos dispositivos son capital lector económico porque facilitan la lectura de una amplia diversidad de textos en línea, aunque estas lecturas son diferentes a las realizadas en libros y tienden a ser mucho más breves y superficiales (Barton, Lee, 2013). 
En casa de Daniel también hay libros: los que son de su madre y los que son de su propiedad. Daniel conserva sus libros en su habitación. Señala que tiene tres de historia de México, Punto ciego, Fahrenheit 451, Nuevas peregrinaciones de Hugo Gutiérrez Vega, algunas novelas de Julio Verne y Romeo y Julieta. Unos cuantos de estos libros son prestados de la biblioteca que nunca devolvió. También posee cómics: de Dare Devil, de los Nova Corps y Punisher mata al universo Marvel.

Los libros de su madre se encuentran en un librero en la sala de la casa. Entre estos, se cuentan algunos tomos de Nietzsche, libros de psicología, medicina, recopilaciones y enciclopedias. Estos libros también forman parte del capital lector de Daniel, pues están a su disposición:

E: ¿Has leído algo de Nietzsche?

Daniel: Pues muy poco sinceramente [...] Es que sabes es... son libros de mi madre, cosas que tienen que ver con psicología y... (cosas) que son más profundas. Recién que agarré la afición por los libros de... también que me puse a leer u-un poco de de esos libros que tenía, sinceramente tampoco entendí nada, porque pienso que... no estaba preparado para leer eso y... que no le podía entender $0 . .$. sabes, para la edad no era lo suficientemente... (Entrevista a Daniel No. 2).

La pequeña biblioteca de su madre también forma parte del capital lector de Daniel, puesto que gracias a ella tiene acceso a lecturas que, aunque no comprende y no estaban destinadas para él, le han dado un panorama sobre ciertas formas de lectura, como pueden ser los libros de psicología. Esto podría vincularse con los resultados obtenidos por Merga (2015), según los cuales, la mera presencia de libros en el hogar predispone a los adolescentes a la curiosidad por la lectura y a una mayor motivación hacia esta. Esto se complementa por lo señalado en el trabajo de Trigo et al., (2020), en el que uno de los hallazgos mostró que una de las razones por las que los jóvenes leen un libro es porque este "estaba en casa".

\section{Capital lector social}

De acuerdo con Compton-Lilly (2007), el capital lector social consiste en las redes sociales que ayudan o permiten llevar a cabo prácticas de lectura. En el caso de Daniel, esta red se compone de amigos, profesores y familiares. Entre los familiares, se identificaron tres principales fuentes de capital lector social: su madre, su hermana mayor y un primo, entre las que destaca la madre como mayor influencia lectora:

$E:$ ¿Tú de dónde crees que... agarraste el gusto [por la lectura]?

Daniel: No lo sé, pues creo que de mi madre, sabes, porque... tenía varios libros ahí y fue como que la curiosidad de... de saber de qué tratan o de qué tienen o cosas así por el estilo.

E: ¿Tu mamá leía cuando tú estabas chico? ¿La veías leer?

Daniel: Más de un ejercicio me tocó verla leer y fue como que de principio le pregunté mamá qué estás haciendo y cosas así por el estilo o porqué lo haces y no sé que tanto. Ya... últimamente no la he visto leer, creo que está muy apresurada o no 
Ser, tener y leer. La identidad lectora y el capital lector: ¿son elementos clave en la configuración de las prácticas lectoras vernáculas de un adolescente de secundaria?

tiene tiempo, cosas así por el estilo, pero... de de chico sí me tocó verla leer al, más de alguna vez.

E: Y cuando le preguntabas ¿qué te decía?

Daniel: Pues fue como... no pues mijo porque... pues me gusta el libro... o me interesó el libro, cosas así por el estilo... nunca me dio que una respuesta certera de por qué (Entrevista a Daniel No. 2).

Las personas que integran el grupo familiar son las principales redes sociales que se convierten en capital lector social para los jóvenes. Particularmente, se ha demostrado que los padres tienen una fuerte influencia en las prácticas lectoras de sus hijos, por un lado, porque son ellos los que suelen invertir dinero en la compra de libros y otros artefactos para la lectura, colaborando así con una buena parte del capital lector económico de sus hijos, y por otro, porque sus valores, ideas y hábitos con respecto a la lectura tienen un peso importante en la formación lectora de sus pequeños (Compton-Lilly, 2007; Jure, Peruchini, 2019). Los padres y madres son frecuentemente modelos a seguir para sus hijos, y para estos últimos, ver a sus progenitores disfrutar de una lectura que gusta y es interesante, como le ocurrió a Daniel con su madre, puede incentivar su interés por la lectura vernácula, como reporta Merga (2014).

Los hermanos también se constituyen en capital lector social. De acuerdo con los hallazgos de Knoester y Plikuhn (2016), los hermanos pueden llegar a tener una fuerte influencia en los hábitos y los gustos lectores de sus hermanos, particularmente de los más jóvenes. La hermana de Daniel es una forma de capital lector social para este porque, aunque no comparten los mismos gustos, en el pasado hablaba con él de literatura, le recomendó lecturas y le prestó libros.

Con quien Daniel podía hablar de cómics interesantes para él, era con un primo ocho años mayor que él. Este primo le introdujo en el mundo de los cómics, pues le mostró que las películas de superhéroes estaban basadas en ellos. De esta forma, Daniel se inició como translector, es decir, según Scolari (2016), un lector capaz de seguir una narrativa haciendo saltos de una plataforma a otra, de películas a cómics en papel, de cómics en papel a su versión en línea:

E: ¿Cuál es la razón, por qué lees cómics?

Daniel: Este... pues también por lo de las películas, así como que, me entró la maña y ya después, eh... ya más grandecito como a los ocho o nueve años... no sé a quién se le escapó el comentario de que jay pero eso no pasó en el cómic! Y no sé qué tanto y yo dije ¡Ah no mames! ¿Hay comics de eso?Y... ya me empezaron a ir que- explicando y... desde el punto actual del que iban fueran explicando qué onda, qué pedo.

$E:$ ¿No te acuerdas quién te dijo?

Daniel: Mi primo [...].

$E$ : ¿Y él te platicaba de eso?

Daniel: Pues sí. Me iba como que explicando las cosas más relevantes en ese momento [...] ... él me enseñó el... me enseñó el-el...formato físico del cómic en, en mis manos, pues, empezaba a leerlo, me, me dio algunas historias del Spiderman del... universo dos ¿veintinueve? Dos ¿noventainueve? (Entrevista con Daniel No. 4). 
El capital lector social no se limita al círculo familiar, sino que se extiende a otros círculos como el de los amigos o la escuela. En el primero de los casos, se ha señalado en otros estudios que el círculo de amigos contribuye a las prácticas lectoras vernáculas de los adolescentes al recomendarse textos, autores e incluso prestarse libros y otros materiales de lectura (Knoester, 2010; Trigo et al., 2020). Daniel tiene un amigo que conoce desde la escuela primaria que cumple con esa función, pues intercambia con él recomendaciones e impresiones de diversos textos, conformando así una parte del capital lector social de Daniel:

E: ¿Y a él [a tu amigo] le gusta leer también?

Daniel: De hecho sí.

$E:$ ¿Y él qué lee?

Daniel: Eh... no lo sé. Él es como un rollo más... poesía y cosas así por el estilo.

$E: ~ ¿ Y$ tú crees que él haya influenciado en tus opciones de lectura?

Daniel: Yo opino que sí, o he leído varios libros de lectura porque él, de lectura, de poesía que, que él me ha dicho: no pos léelo está interesante o... cuando ya agarres el rollo te va- te va tar- te va a atrapar y vas a ques- querer seguir leyendo y yo digo: Ah ps está bien y, de hecho el de Nuevas Peregrinacio-Peregrinaciones él me lo... él me lo... ¿cómo se llama?... recomendó y ... pues me pareció bien, me pareció- de hecho es uno de los- de mis libros favoritos desde el momento, digo, pues... (Entrevista a Daniel No. 4).

En la escuela, algunos profesores se han constituido como capital lector social para las prácticas lectoras vernáculas de Daniel. Él refiere que hay profesores con los que ocasionalmente puede hablar de lectura, a diferencia de sus compañeros, con los que no le es posible "entablar una conversación sólida sobre libros". Específicamente, recuerda a una profesora que le enseñó Historia en segundo grado y con la que compartía el interés por el rap y el hip hop; esta docente le regaló el libro de Fahrenheit 451, que aún conserva y que forma parte de su capital lector económico. Cabe mencionar que este libro tiene particular relevancia para el capital lector de Daniel, pues además de ser una forma de capital económico, constituye capital simbólico o, en palabras de Bourdieu (2001), capital "aprehendido simbólicamente", porque la ideología y los valores contenidos en el libro, en el que la lectura como actividad prohibida en un mundo distópico toma un papel protagónico, son elementos que contribuyen en la percepción de Daniel con respecto al libro y la lectura.

Como se puede ver, el capital social de Daniel podría describirse como una red que se compone de varias líneas que proceden de los diversos contextos en los que se desenvuelve, tales como el hogar, la escuela y el de los amigos. Este capital social aporta a Daniel diversos elementos que enriquecen su relación con la lectura vernácula: el conocimiento de nuevos textos, autores y formatos de lectura, ideas, emociones y valores que consolidan su identidad lectora y nuevos materiales de lectura que se han incorporado a su capital lector económico. 


\section{Capital lector cultural}

Como ya se señaló arriba en este documento, el capital lector cultural consta de tres elementos: las evidencias de la capacidad lectora (capital lector cultural objetivado), la trayectoria lectora e institucional (capital lector institucionalizado) y la incorporación o interiorización de las prácticas y las disposiciones hacia la lectura, provenientes de los contextos en los que el sujeto se desenvuelve, es decir, el capital lector incorporado (Compton-Lilly, 2007; Suárez, Alarcón, 2015).

El capital lector cultural objetivado de Daniel consiste en su capacidad para hablar y discutir con facilidad sobre las lecturas que ha realizado: ha descrito los temas que le interesan y los que no son de su agrado, desarrolla las tramas que contienen ciertas historias que ha leído y puede ofrecer algunos datos sobre la información que ha obtenido en internet sobre temas de su interés, incorporando además sus propias opiniones. Estas evidencias de su capacidad para la lectura se limitan a las lecturas vernáculas porque, en relación con las lecturas oficiales, el capital lector cultural objetivado de Daniel muestra otra cara:

\section{E: ¿Y cómo lee [Daniel]?}

Maestra: Pues lee bien, o sea no, lee bien, pero no comprende lo que lee, muchas veces [...] porque, porque cuando este... le pregunto tarda tiempo en responder y me dice "ay es que no me acuerdo". O como... es que esa materia se presta porque es lo que ven cotidianamente. Entonces ya cuando con una palabra que lean o un concepto que ellos leen, este, lo relacionan con su vida diaria, es la, es la manera como, como este, te responden. (Entrevista a la profesora de Daniel).

Para la maestra entrevistada, Daniel "lee bien", pero no comprende lo que lee. Por lo que ella señala, podría decirse que el desinterés de Daniel por la materia impartida le lleva a no tomar en serio la lectura de los textos académicos en esa clase. Su capital lector cultural objetivado, en este caso, escolar, está marcado por su falta de compromiso con la escuela. Sin embargo, como señalan Cassany y Hernández (2012), el hecho de que los adolescentes no cumplan a cabalidad con las demandas académicas en cuanto a lectura se refiere, no significa que estos no posean un "capital letrado" rico y variado, aunque alejado de las prácticas lectoras escolares convencionales, como Daniel lo muestra cuando habla sobre sus lecturas vernáculas.

El capital lector institucionalizado de Daniel muestra una relación conflictiva con la lectura escolar. Daniel señala que habitualmente reprueba la materia de Español y, en general, sus calificaciones tienden a ser mediocres. En su familia, sin embargo, hay cierta tradición lectora y sus miembros han adquirido capital lector institucionalizado: su madre estudió psicología, su padre, derecho; su hermana mayor es estudiante de la carrera de enfermería.

A pesar de tener un capital lector institucionalizado que se distingue por las bajas notas en la escuela, el capital lector incorporado de Daniel se caracteriza por la interiorización de prácticas lectoras vernáculas y de la favorable disposición hacia ellas en los contextos en que se desenvuelve. Esto significa que en la familia, en la escuela o entre amigos, se han efectuado prácticas 
de lectura vernácula que han dejado su huella en Daniel y este ha incorporado tales prácticas, ha adquirido esas formas de leer y el gusto por ello. Por el contrario, aunque ha habido interiorización de las prácticas lectoras escolares en Daniel durante sus años de escuela, la disposición hacia ellas, aunque no es nula, sí que es limitada.

Lo anterior es un ejemplo de las tensiones entre prácticas de lectura vernáculas y oficiales. De acuerdo con Compton-Lilly (2007), estas tensiones se manifiestan en la devaloración de las prácticas lectoras vernáculas que las instituciones oficiales como la escuela ejercen de manera casi sistemática y en la existencia de esas prácticas lectoras como prácticas de resistencia que son producto del contexto mismo en el que son llevadas a cabo (Hernández, 2009). Estas tensiones no existen únicamente en el contexto del aula, sino que se trasladan a los demás contextos, como el familiar o el de los amigos. Leer lecturas vernáculas y no leer las lecturas oficiales es un acto de protesta, un camino de la definición de la propia identidad lectora y de la identidad en general, que Daniel transita como adolescente.

\section{Consideraciones finales}

En este estudio piloto se planteó como primer objetivo explorar la identidad lectora, el capital lector y la práctica lectora vernácula de un estudiante de secundaria, así como sus posibles relaciones. A partir del análisis de cada uno de los componentes de estas variables se encontró que las diferentes prácticas lectoras vernáculas realizadas por Daniel obedecen a sus propias necesidades e intereses, pero también se vinculan estrechamente con las emociones, sentimientos, cogniciones y valoraciones (su identidad lectora) generadas en él a partir de su relación con la lectura y su entorno. Su identidad lectora le decanta por la elección y desarrollo de ciertas lecturas vernáculas, al mismo tiempo que las lecturas vernáculas que realiza por influencia de otras personas aportan en la configuración de su identidad lectora. Esto significa que su capital lector social (es decir, sus redes sociales lectoras), está involucrado en la construcción de valores y significados de Daniel hacia la lectura; dicho capital lector social aporta otras formas de capital lector, económico y cultural que, de manera intrincada, contribuyen también en la configuración de su perfil lector.

Estos resultados, sin embargo, no pueden ser generalizados, pues el estudio se limitó al caso de un solo adolescente. Como se recordará, el segundo objetivo fue valorar la pertinencia de las técnicas e instrumentos propuestos para el estudio y análisis de las relaciones entre identidad lectora, capital lector y prácticas lectoras vernáculas de adolescentes. Los resultados muestran que la observación y la técnica de la entrevista semiestructurada, de la mano con el "guion de las entrevistas", son herramientas pertinentes para la construcción de datos cualitativos que den cuenta de estos componenetes. Además, las estrategias utilizadas para el análisis de los datos, basadas en el enfoque orientado hacia la comprensión de personas y contextos de Taylor y Bogdan (1987), permitieron obtener algunos hallazgos que pueden ser de utilidad para explicar las relaciones entre las tres variables de interés para este trabajo. 
Se encontró también que el instrumento diseñado para el autorregistro de las lecturas fue ineficaz para su propósito, pues al no ser una actividad que generara interés en el informante, ninguno de los formatos fue completado ni entregado a la entrevistadora. Esto supone la búsqueda y adecuación de otros instrumentos que, además de que permitan indagar a profundidad sobre las lecturas vernáculas realizadas por los adolescentes, sean lo suficientemente interesantes para ellos.

Cabe mencionar que el desarrollo de las prácticas vernáculas de los adolescentes tiene múltiples aristas que aún deben ser investigadas. Por ejemplo, el fenómeno de la transmedialidad (Scolari, 2016; Barton, Lee, 2013), que se caracteriza por que textos y lecturas rebasan los soportes en los que surgieron o venían ocurriendo y que de acuerdo con Albarello (2019), es la consecuente evolución de la lectura digital y de la lectura en general, en la que soportes análogos y multipantallas conviven conformando una especie de "ecosistema lector". Estudiar las prácticas lectoras vernáculas, y en general las prácticas de lectura de los adolescentes como un ecosistema lector es, quizás, el siguiente paso en la investigación de la lectura. Finalmente, es necesario ampliar los estudios de esta naturaleza a adolescentes de diversos géneros, contextos culturales y niveles socioeconómicos, pues los resultados de este trabajo, centrado en un solo joven varón, muestran solamente una pincelada del gran paisaje que es el estudio de la práctica lectora.

\section{Referencias}

Albarello, F. (2019). Leer, escribir, conversar en el ecosistema de pantallas. Ampersand.

Aliagas, C.; J. M. Castellà; D. Cassany (2009). Aunque lea poco, yo sé que soy listo. Estudio de caso sobre un adolescente que no lee literatura. Revista OCNOS, (5), 97-112.

Barton, D.; M. Hamilton (2012). Local Literacies. Reading and Writing in One Community. Nueva York: Routledge.

Barton, D.; C. Lee (2013). Language Online. Investigating Digital Texts and Practices. Londres/Nueva York: Routledge.

Bourdieu, P. (2001). Poder, derecho y clases sociales. Desclée de Brouwer.

Cassany, D.; D. Hernández (2012). ¿Internet: 1; Escuela: 0? CPU-e, Revista de Investigación Educativa, (14), 126-141.

Compton-Lilly, C. (2007). The Complexities of Reading Capital in Two Puerto Rican Families. Reading Research Quarterly, 42(1), 72-98. https://doi.org/10.1598/RRQ.42.1.3

Coffey, A.; P. Atkinson (2003). Encontrar el sentido a los datos cualitativos. Estrategias complementarias de investigación. Medellín: Universidad de Antioquia.

Dallo, V.; N. Soler (2019). En busca de'lo literario': Análisis de autobiografías lectoras en estudiantes ingresantes a las carreras de Lenguas Extranjeras. En Jure, M. G.; G. A. Sergi (comps.). 
Nuevas consideraciones acerca de la lectura. Literatura, historia y cultura visual. Argentina: UniRío, 130-145.

Fontana, A.; J. H. Frey (2000). The Interview: from Structured Questions to Negotiation Text. En Denzin, N. K.; Y. S. Lincoln (eds.). Handbook of Qualitative Research. Second edition. Estados Unidos: Sage Publications, 645-672.

Fulmer, S. M.; M. Tulis (2013). Changes in Interest and Affect During a Difficult Reading Task: Relationships with Perceived Difficulty and Reading Fluency. Learning and Instruction, (27), 11-20. https://doi.org/10.1016/j.learninstruc.2013.02.001

Gee, J. P. (2000). The New Literacy Studies: from 'Socially Situated' to the Work of the Social. En Barton, D.; M. Hamilton; R. Ivanič (eds.). Situated Literacies. Reading and Writing in Context. Nueva York: Routledge, 180-196.

González, M. (2002). Aspectos éticos de la investigación cualitativa. Revista lberoamericana de Educación, (29), 85-103.

González, Y. (2013). La lectura en contextos laborales y escolares. Guadalajara: Universidad de Guadalajara.

Hamilton, M. (2000). Expanding the New Literacy Studies. Using Photographs to Explore Literacy as Social Practice. En: Barton, D.; M. Hamilton; R. Ivanič (eds.). Situated Literacies. Reading and Writing in Context. Nueva York: Routledge, 16-34.

Hernández, G. (2009). Identidades juveniles y cultura escrita. En Kalman, J.; B. Street (coords.). Lectura, escritura y matemáticas como prácticas sociales. México: Siglo XXI, 186-201.

Jure, M. G.; A. Peruchini (2019). Estudio de la identidad lectora de los estudiantes ingresantes a las carreras de lenguas extranjeras en la universidad como futuros mediadores de lecturas. En Jure, M. G.; G. A. Sergi (comps.). Nuevas consideraciones acerca de la lectura. Literatura, historia y cultura visual. Argentina: UniRío, 117-129.

Knoester, M. (2010). Independent Reading and the'Social Turn': How Adolescent Reading Habits and Motivation Relate to Cultivating Social Relationships. Networks, 12(1), 1-13.

Knoester, M.; M. Plikuhn (2015). Influence of Siblings on out-of-School Reading Practices. Journal of Research in Reading, 00(00), 1-17. https://doi.org/10.1111/1467-9817.12059

Manresa, M.; A. M. Margallo. (2016). Prácticas de lectura en red: exploración de blogs literarios adolescentes. Catalejos. Revista sobre lectura, formación de lectores y literatura para niños, 2(3), 51-69.

Martínez, F. J. (2014). Prácticas letradas de universitarios mexicanos: la "rivalidad" entre papel y pantalla. En Colomer, T.; M. Manresa (coords.). La literatura en pantalla: textos, lectores y prácticas docentes. Simposio llevado a cabo en la Universitat Autònoma de Barcelona, Barcelona.

Merga, M. K. (2014). Exploring the Role of Parents in Supporting Recreational Book Reading beyond Primary School. English in Education, 48(2), 149-163. https://doi.org/10.1111/eie.12043 
Merga, M. K. (2015). Access to Books in the Home and Adolescent Engagement in Recreational Book Reading: Considerations for Secondary School Educators. English in Education, 49(3), 197-214. https://doi.org/10.1111/eie.12071

Orozco, R.; M. Barahona (2019). Hábitos y disposiciones hacia lectura recreacional entre la población estudiantil de la Universidad Estatal a Distancia de Costa Rica. Una aproximación sociológica desde el capital cultural. En Olaza, M.; F. Arocena; E. A. Sandoval (coords.). Sociología de la cultura, arte e interculturalidad. Buenos Aires: Teseo, 171-190.

Prensky, M. (2013). Enseñar a nativos digitales. México: SM.

Petit, M. (2011). Nuevos acercamientos a los jóvenes y la lectura. México: Fondo de Cultura Económica.

Rodríguez, G.; J. Gil; E. García (1999). Metodología de la investigación cualitativa. Málaga: Aljibe.

Scolari, C. A. (2016). El translector. Lectura y narrativas transmedia en la nueva ecología de la comunicación. En Millán, J. A. (coord.). La lectura en España: Informe 2017. España: Federación de Gremios de Editores de España.

Suárez, J. L.; J. F. Alarcón (2015). Capital cultural y prácticas de consumo cultural en el primer año de estudios universitarios. Revista Interamericana de Educación de Adultos, 37(1), 42-62.

Taylor, S. J.; R. Bogdan (1987). Introducción a los métodos cualitativos de investigación. La búsqueda de significados. México: Paidós.

Trigo, E.; I. C. Santos; S. Sánchez (2020). ¿Qué leen los adolescentes españoles? Un estudio de los consumos de lectura analógica. Investigaciones sobre Lectura, (13), 54-71. https://doi.org/10.37132/isl.v0i13.278

Valdez, D. (2017). Lecturas vernáculas entre jóvenes de nivel medio superior de la Zona Metropolitana de Guadalajara. En Rodríguez, Z. (coord.). Cultura, discursos y experiencias subjetivas: análisis empíricos en México. Guadalajara: Universidad de Guadalajara, 189-216.

Villalpando, M. E. (2014). Consumo cultural del libro y la lectura en estudiantes de secundaria en Jalisco. Revista Electrónica de Investigación Educativa, 16(3), 54-70.

World Health Organization (2017). Informed Consent for Qualitative Studies.

http://www.who.int/rpc/research ethics/informed consent/en/ 